\title{
NGHIỂN MẠNG XÃ HộI VÀ SỰ TÁC ĐộNG CỦA NGHIỆN MẠG XÃ HộI ĐẾN HỌC SINH TRƯờ'NG TRUNG HỌC CƠ SỞ MINH TRÍ NĂM 2019
}

\author{
Phạm Thị Kim Yến', Thạch Thị Mỹ Phương1 \\ Thạch Thị Thi Huy ${ }^{1}$, Nguyễn Văn Lo ${ }^{2}$
}

\section{TÓM TẮT}

Mạng xã hội là thuật ngữ phổ biến trong cuộc sống hàng ngày của mối cá nhân với những tính năng đa dạng, nguồn thông tin phong phú, cho phép người dùng tiếp nhận, chia sẻ thông tin một cách nhanh chóng và hiệu quả. Theo số liệu của Trung tâm Internet Việt Nam (2012), số người sử dụng internet đã lên tới 31,1 triệu người, chiếm tỷ lệ $35,49 \%$ dân sô [3]. Nghiên cứu với mục tiêu là xác định tỷ lệ nghiện mang xã hội và sự tác động của nghiện mạng xã hội đển học sinh trường Trung học cơ sở Minh Trí năm 2019. Nghiên cứu khảo sát 195 hoc sinh trường Trung học cơ sở Minh Trí có 39,0\% học sinh nghiện mạng xã hội. Bên cạnh đó, nghiên cứu còn tìm thấy mối liên quan giữa sự tác động nghiện mạng xã hội với sử dụng instsgram, chất lượng giấc ngủ, ngại giào tiếp, ít tham gia các hoạt động tập thể của học sinh, mất tập trung hay giảm thời gian học, đau mắt/khô mắt/giảm thị lực, kết quả học tập của học sinh. Qua kết quả của nghiên cứu cân có kế hoạch truyền thông giáo dục sức khỏe phù hợp cho học sinh trường Trung học cơ sở Minh Trí nói riêng cũng như học sinh Trung học cơ sở nói chung về hành vi sử dụng mạng xã hội một cách phù hợp để không ảnh hưởng đến kết quả học tập cũng như cuộc sống của học sinh để góp phần làm nâng cao kết quả học tập của học sinh trung học cơ sở. sinh.

Tư khóa: Mạng xã hội, trường THCS Minh Trí, học

\section{SUMMARY \\ SOCIAL NETWORK ADDICTION AND THE IMPACT OF SOCIAL NETWORK ADDICTIONON A STUDENT OF MINH TRI JUNIOR HIGH SCHOOL IN 2019}

The social network is a popular term in the daily life of each individual with diverse features, rich information sources, allowing users to receive and share information quickly and effectively. According to data of Vietnam Internet Center (2012), the number of internet users has reached 31.1 million, accounting for about $35.49 \%$ of the population [3]. Research with the objective is to determine the rate of social network addiction and the impact of social network addiction on students of Minh Tri Junior High School in 2019.A survey of 195 students at Minh Tri junior high school found that $39.0 \%$ of students were addicted to social

\footnotetext{
${ }^{1}$ Trường Đại học Trà Vinh

${ }^{2}$ Trung tâm Kiểm soát bệnh tật Trà Vinh Chịu trách nhiệm chính: Phạm Thị Kim Yến Email: yenphamytcc@tvu.edu.vn Ngày nhận bài: 10/8/2021

Ngày phản biện khoa học: 31/8/2021

Ngày duyệt bài: 27/9/2021
}

networks. Besides, The study found a relationship between the impact of social network addiction with Instagram use, sleep quality, shyness in communication, less participation in student activities, distraction or reduced study time, eye pain/dry eyes/reduced vision, student academic performance. Through the study results, it is necessary to have an appropriate health education communication plan for students of Minh Tri junior high school in particular and junior high school students in general about the behavior of using alcohol. social networks in an appropriate way so as not to affect the learning results as well as the lives of students to contribute to improving the learning results of junior high school students.

Keywords: Social network, Minh Tri junior high school, student.

\section{I. ĐĂT VẤN ĐỀ}

Theo thống kê trong năm 2016, hơn 3,4 tỷ người trên thế giới sử dụng mạng internet, chiếm khoảng 40\% dân số thế giới. Theo số liệu của Trung tâm Internet Việt Nam (2012), số người sử dụng internet đã lên tới 31,1 triệu người, chiếm tỷ lệ $35,49 \%$ dân số. Việt Nam đứng thứ $18 / 20$ quốc gia có số người sử dụng internet lớn nhất thế giới, đứng thứ 8 trong khu vực Châu Á và đứng vị trí thứ 3 ở khu vực Đông Nam Á [3].

Tuy nhiên, các trang mạng xã hội phát triển cũng đã kéo theo nhiêu hệ lụy liên quan. Nghiện mạng xã hội cũng được xem như là một trong những căn bệnh nguy hiểm - một cắn bệnh không gây đau đớn thể xác nhưng nó lại mang đến vô vàn nguy hại, một sự báo động lớn cho thế giới hôm nay. Nhiều nghiên cứu cũng cho thây sức ảnh hưởng cả về ưu điểm hay tác hại của việc sử dụng mạng xã hội. Mạng xã hội đã giúp con người trao đổi nâng cao kiến thức, đáp ứng nhu cầu giải trí, công cụ đắt lực hố trợ công việc trong nhiều lĩnh vực: dịch vụ, thương mại, quảng bá, $y$ tế, truyền thổng, học tập... Mặt khác, nó sẽ trở thành mối lo ngại lớn nếu ta sử dụng không đúng.

Trà Vinh là một trong những tỉnh lẻ còn gặp nhiều vấn đề khó khăn. Vấn đề giáo dục, chăm sóc sức khỏe trẻ em, thế hệ trẻ của địa phương, là vấn đề ưu tiên những cần phải có sự quan tâm nhiều hơn nhất là sức khỏe tinh thần của các em. Do học sinh dễ bị tác động bởi những cái mới, nếu học hỏi, tiếp thu và sử dụng không đúng cách sẽ gây nhiêu hệ lụy về sau. Trường 
Trung học cơ sở Minh Trí là một trong những trường điểm thuộc khu vực Thành phố Trà Vinh. Nhằm phân tích và tìm hiểu hiện trạng sử dụng mạng xã hội của học sinh trường Trung học cơ sở Minh Trí hiện nay cũng như những tác động của mạng xã hội đến học sinh như thế nào, từ đó đưa ra những khuyến cáo nhằm hạn chế những mặt hại và nâng cao mặt tích cực mà mạng xã hội đem lại.

\section{II. ĐỐI TƯợNG VÀ PHƯƠNG PHÁP NGHIÊN CỨU}

2.1. Thiết kế nghiên cứu: Cắt ngang mô tả

2.2. Đối tượng nghiên cứu: Học sinh đang

\section{KẾT QUẢ NGHIÊN CứU}

Bảng 1. Đặc điểm dân số - kinh tế - xã hội của đối tượng nghiên cứu(n=195)

\begin{tabular}{|c|c|c|c|c|c|c|c|}
\hline \multicolumn{2}{|c|}{ Đặc điểm } & \multirow{2}{*}{$\begin{array}{c}\begin{array}{c}\text { Tấn } \\
\text { số }\end{array} \\
98\end{array}$} & \multirow{2}{*}{$\begin{array}{c}\begin{array}{c}\text { Tỷ lệ } \\
(\%)\end{array} \\
50,3\end{array}$} & \multicolumn{2}{|c|}{ Đặc điểm } & \multirow{2}{*}{$\begin{array}{c}\text { Tấn số } \\
150\end{array}$} & \multirow{2}{*}{$\begin{array}{c}\begin{array}{c}\text { Tỷ lệ } \\
(\%)\end{array} \\
76,9\end{array}$} \\
\hline Giới tính & Nam & & & \multirow{3}{*}{$\begin{array}{l}\text { Phương tiện } \\
\text { truy cập } \\
\text { mạng }\end{array}$} & $\begin{array}{c}\text { Thiết bị di động } \\
\text { cá nhân }\end{array}$ & & \\
\hline & Nũ̃ & 97 & 49,7 & & Máy vi tính & 23 & 11,8 \\
\hline \multirow{2}{*}{ Dân tộc } & Kinh & 151 & 77,4 & & Tất cả ý trên & 22 & 11,3 \\
\hline & Khác & 44 & 22,6 & \multirow{2}{*}{$\begin{array}{l}\text { Thành tích } \\
\text { học tập }\end{array}$} & $\geq$ Trung bình & 39 & 20,0 \\
\hline $\begin{array}{l}\text { Kinh tế } \\
\text { gia đinh }\end{array}$ & $\begin{array}{l}\text { Hộ nghèo } \\
\text { Khônq nahèo }\end{array}$ & $\begin{array}{c}11 \\
184\end{array}$ & $\begin{array}{c}5,6 \\
94,4\end{array}$ & & $<$ Trung bình & 156 & 80,0 \\
\hline
\end{tabular}

Số học sinh nam và nữ tham gia vào nghiên cứu có sĩ số gân như nhau lần lượt là $50,3 \%$ và 49,7\%. Dân tộc Kinh (77,4\%) có tỷ lệ cao gấp khoảng 3,8 lần so với nhóm dân tộc khác (Khmer, Hoa, Chăm). Đa số học sinh có điều kiện kinh tế gia đình thuộc nhóm không nghèo (94,4\%). Học sinh có kết quả học tập chủ yếu trên trung bình (khá, giỏi, xuất sắt) chiếm $80 \%$. Phân lớn học sinh truy cập mạng xã hội bằng thiết bị di động cá nhân (điện thoại, ipad...) chiếm 76,9\%.

Bảng 2. Đắc điểm sư dụng mạng xã̃ hội của đôi tượng $(n=195)$

\begin{tabular}{|c|c|c|c|c|c|c|c|}
\hline \multicolumn{2}{|c|}{ Đặc điếm } & Tấn số & Tỷ lệ (\%) & \multicolumn{2}{|c|}{ Đặc điếm } & Tấn số & Tỷ lệ (\%) \\
\hline \multirow{3}{*}{$\begin{array}{l}\text { Sử dụng } \\
\text { mạng xã hội }\end{array}$} & Có & 195 & 100 & \multirow{3}{*}{$\begin{array}{c}\text { Nhân địnnh } \\
\text { về mạng } \\
\text { xã hội }\end{array}$} & Có lợi & 10 & 5,2 \\
\hline & \multirow{2}{*}{ Không } & \multirow{2}{*}{0} & \multirow{2}{*}{0} & & Có hại & 2 & 1,0 \\
\hline & & & & & Cả hai & 183 & 93,8 \\
\hline
\end{tabular}

$100 \%$ học sinh tham gia nghiên cứu đều có sử dụng mạng xã hội. Học sinh chủ yếu nhận định việc sử dụng mặng xã hội đều có 2 mặt (có lợi và cả có hại) của mạng xã hội.

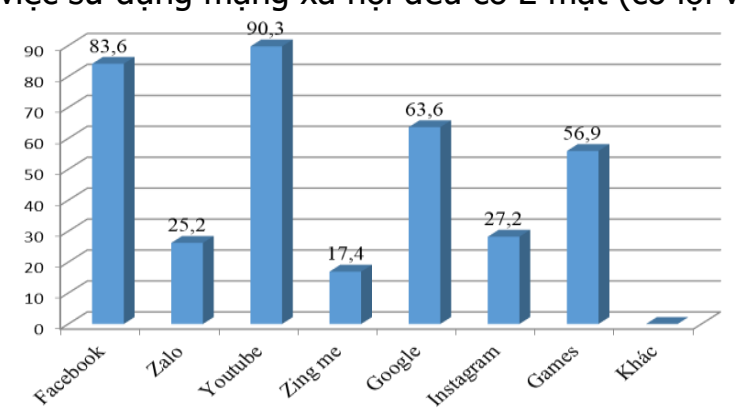

Biêu đơ̂̉ 1. Những trang mạng học sinh trường Trung học cơ sở Minh Trí sử dụng

Phân lớn học sinh thường sử dụng các trang mạng xã hội như: youtube $(90,3 \%)$, facebook $(83,6 \%)$, google $(63,6 \%)$, game $(56,9 \%)$. Ngược lại, các trang mạng zalo, zing me, instagram và nhóm khác thì ít được sử dụng.

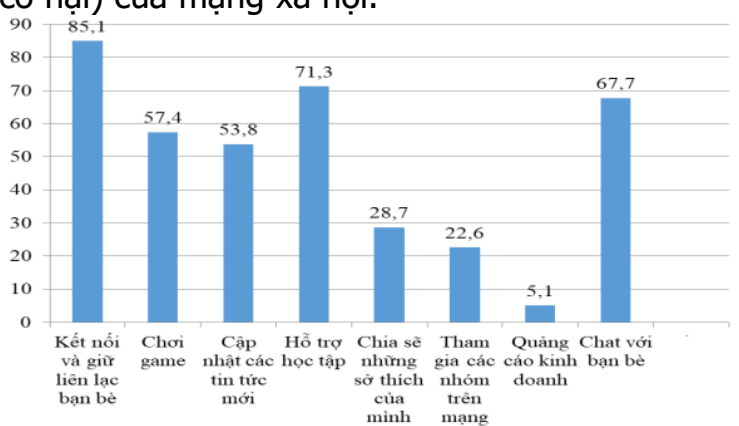

Biểu đồ 2. Mục đích sử dụng mạng xã hội của đôi tượng nghiên cứu

Có sự chênh lệch giữa các mục đích sử dụng các trang mạng xã hội của học sinh như: sứ dụng mạng xã hội để kết nối và giữ liên lạc bạn bè chiếm tỷ lệ cao nhất $(85,1 \%)$, tiếp đến hỗ trợ học tập $(71,3 \%)$, chat với bạn bè $(69,7 \%)$. 
Sử dụng để chơi game, cập nhật các tin tức mới chiếm tỷ lệ sử dụng ở mức trung bình có tỷ lệ lần lượt là $57,4 \%$ và $53,8 \%$. Còn lại, chia sẽ những sở thích của mình, tham gia các nhóm trên mạng, quảng cáo kinh doanh và nhóm các mục đích khác đều chiếm tỷ lệ thấp lần lượt là $28,7 \%, 22,6 \%, 5,1 \%$.

Bảng 3: Tác động của mạng xã hội với đối tượng (n=195)

\begin{tabular}{|c|c|c|c|c|c|c|c|}
\hline \multicolumn{2}{|l|}{ Đặc điểm } & $\begin{array}{l}\text { Tấn } \\
\text { số }\end{array}$ & $\begin{array}{l}\text { Tỷ lề } \\
(\%)\end{array}$ & \multicolumn{2}{|c|}{ Đặc điểm } & Tấn số & $\begin{array}{l}\text { Tỷ lệ } \\
(\%)\end{array}$ \\
\hline \multirow{2}{*}{$\begin{array}{l}\text { Mất ngủ hay cảm } \\
\text { thây uể oải do ngủ } \\
\text { không đủ }\end{array}$} & Có & 32 & 16,4 & \multirow{2}{*}{$\begin{array}{l}\text { Đau mắt, khô } \\
\text { mắt hay giảm } \\
\text { thị lực }\end{array}$} & Có & 78 & 40 \\
\hline & Không & 163 & 83,6 & & Không & 117 & 60 \\
\hline \multirow{2}{*}{$\begin{array}{l}\text { Ngại giao tiếp, ít } \\
\text { tham gia hoạt } \\
\text { động tập thể }\end{array}$} & Có & 55 & 28,2 & \multirow{4}{*}{$\begin{array}{l}\text { Cảm nhận về } \\
\text { sức khỏe sau } \\
\text { khi sử dụng } \\
\text { mạng xã hội }\end{array}$} & \multirow{2}{*}{$\begin{array}{c}\text { Thoải mái, } \\
\text { bình } \\
\text { thường }\end{array}$} & \multirow[b]{2}{*}{193} & \multirow[b]{2}{*}{99,0} \\
\hline & Không & 140 & 71,8 & & & & \\
\hline \multirow{2}{*}{$\begin{array}{l}\text { Gây mất tập trung } \\
\text { trong học tập hay } \\
\text { giảm thời gian học }\end{array}$} & Có & 31 & 15,9 & & \multirow{2}{*}{$\begin{array}{l}\text { Mêt mỏi, } \\
\text { căng thẳng }\end{array}$} & \multirow{2}{*}{2} & \multirow{2}{*}{1,0} \\
\hline & Không & 164 & 84,1 & & & & \\
\hline \multirow{2}{*}{\multicolumn{4}{|c|}{$\begin{array}{l}\text { Đa số học sinh cảm thấy sức khỏe bình } \\
\text { hường }(99,0 \%) \text { sau khi sữ dụng mạng xã hội và } \\
\text { chỉ có } 1 \% \text { số học sinh cảm thấy mệt mỏi, căng }\end{array}$}} & & chuấn & nhất & nhất \\
\hline & & & & $\begin{array}{l}\text { Tổng điểm theo } \\
\text { thang đo IAT }\end{array}$ & $\begin{array}{l}28,12+/ \\
-12,891 \\
\end{array}$ & 0 & 60 \\
\hline
\end{tabular}

thẳng sau những lần truy cập mạng xã hội.

Tác hại của sử dụng mạng xã hội gây ra khá cao: đau mắt, khô mắt hay giảm thị lực chiếm 40\%; ngại giao tiếp ít tham gia hoạt động tập thể chiếm 28,2\%; 15,9\% trên tổng số học sinh điều tra cảm thấy mất tập trung trong học tập hay giảm thời gian học do sử dụng mạng; học sinh bị mất ngủ hay cảm thây uể oải do ngủ không đủ chiếm 16,4\%.

Bảng 4. Đặc điểm hoạt động thể lực của đố tượng $(n=195)$

\begin{tabular}{|c|c|c|}
\hline Hoạt động thể lực & $\begin{array}{c}\text { Tân } \\
\text { số (n) }\end{array}$ & $\begin{array}{c}\text { Tỷ lệ } \\
(\mathbf{\%})\end{array}$ \\
\hline Hoạt động thể lực tốt & 88 & 45,1 \\
\hline Hoạt động thế lực không tốt & 107 & 54,9 \\
\hline
\end{tabular}

Hoc sinh tham gia nghiên cứu có hoạt động thể lực không tốt chiếm tỷ lệ cao 54,9\%.

Bảng 5. Đặc điểm sử dụng mạng theo thang đo IAT của đôi tượng

\begin{tabular}{l|l|l|l|} 
Đặc điểm & TB+/- độ lệch & Nhỏ & Lớn \\
\hline
\end{tabular}

Điểm trung bình nghiên internet theo thang đo IAT là $28,12+/-12,891$.

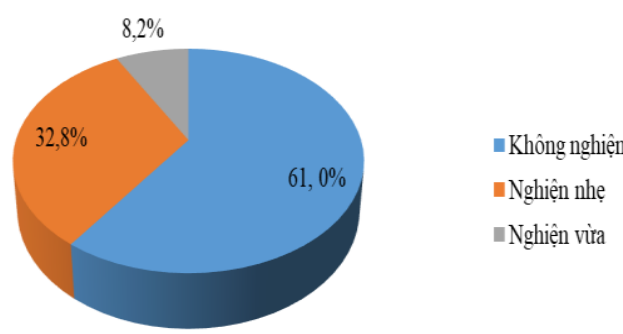

Biểu đồ 3. Thực trạng nghiện mạng xã hội của đối tượng nghiên cứu

Tỷ lê nghiện mạng xã hội của học sinh tham gia nghiên cứu khá cao $(39,0 \%)$. Trong đó học sinh nghiện ở mức độ nhẹ chiếm 38,8\%, nghiện ở mức độ vừa chiếm $8,2 \%$ và không có trường hợp nghiện mạng xã hội ở mức nặng.

Bảng 6. Mối liên quan giữa trang mạng học sinh sử dụng với nghiện mạng xã hội $(n=195)$

\begin{tabular}{|c|c|c|c|c|c|}
\hline \multirow{2}{*}{\multicolumn{2}{|c|}{ Đặc điểm }} & \multicolumn{2}{|c|}{ Nghiện mạng xã hội } & \multirow[b]{2}{*}{$\mathbf{p}$} & \multirow{2}{*}{$\begin{array}{c}\text { OR } \\
\text { (KTC 95\%) }\end{array}$} \\
\hline & & Có n (\%) & Không n(\%) & & \\
\hline \multirow[b]{2}{*}{ Instagram } & Có & $29(54,7)$ & $24(45,3)$ & \multirow{2}{*}{0,006} & 2,442 \\
\hline & Không & $47(33,1)$ & $95(66,9)$ & & $(1,283-4,650)$ \\
\hline \multirow{2}{*}{ Game } & Có & $52(46,8)$ & $59(53,2)$ & \multirow{2}{*}{0,01} & 2,203 \\
\hline & Không & $24(28,6)$ & $60(71,4)$ & & $(1,206-4,025)$ \\
\hline
\end{tabular}

Học sinh sử dụng mạng instagram có tỷ lệ nghiện mạng xã hội cao gấp 2,442 lần (95\% CI: 1,283$4,650)$ so với nhóm không sử dụng. Sự khác biệt này có ý nghĩa thống kê với $p=0,006$.

Học sinh sử dụng mạng game có tỷ lệ nghiện mạng xã hội cao gấp 2,203 lần (95\% CI: 1,206$4,025)$ so với nhóm không sử dụng. Sự khác biệt này có ý nghĩa thống kê với $p=0,01$.

Bảng 7. Sự tác động của nghiện mạng xã hội với thành tích học tập (n=195)

\begin{tabular}{|c|c|c|c|c|}
\hline \multirow{2}{*}{$\begin{array}{l}\text { Nghiện mạng } \\
\text { xã̃ hội }\end{array}$} & \multicolumn{2}{|c|}{ Xếp loại học tập } & \multirow{2}{*}{$\begin{array}{c}\text { OR } \\
\text { (KTC 95\%) }\end{array}$} & \multirow[b]{2}{*}{$\mathbf{P}$} \\
\hline & $\begin{array}{l}\text { Dưới trung bình, } \\
\text { trung bình n }(\%)\end{array}$ & $\begin{array}{c}\text { Trền trung bình } \\
n(\%)\end{array}$ & & \\
\hline
\end{tabular}




\begin{tabular}{|c|c|c|c|c|}
\hline Có & $21(27,6)$ & $55(72,4)$ & 2,142 & \multirow{0}{*}{0,033} \\
\hline Không & $18(15,1)$ & $101(84,9)$ & $(1,053-4,358)$ & \\
\hline
\end{tabular}

Học sinh bị nghiện mạng xã hội thì có học lực trung bình, dưới trung bình cao gấp 2,142 lần (95\% CI: 1,053-4,358) so với học sinh không bị nghiện mạng xã hội. Sự khác biệt này có ý nghĩa thống kê với $\mathrm{p}=0,033$.

Bảng 8. Sự tác động của nghiện mạng xã hội với chất lượng giấc ngủ ( $n=195)$

\begin{tabular}{|c|c|c|c|c|}
\hline $\begin{array}{c}\text { Nghiện mạng } \\
\text { xã hội }\end{array}$ & \multicolumn{2}{|c|}{ Mất ngủ hay cảm thấy uể oải do ngủ không đủ } & $\begin{array}{c}\text { OR } \\
\text { (KTC 95\%) }\end{array}$ & p \\
\hline Cón & Có $n(\%)$ & Không $n(\%)$ & \\
\hline Không & $21(27,6)$ & $55(72,4)$ & 3,749 & $\mathbf{0}, \mathbf{0 1}$ \\
\hline
\end{tabular}

Nhóm học sinh bị nghiện mạng xã hội thì có chất lượng giấc ngủ không tốt cao gấp 3,749 (95\% CI: 1,687-8,330) so với nhóm học sinh không nghiện mạng xã hội. Sự khác biệt này có ý nghĩa thống kê với $\mathrm{p}=0,01$.

Bảng 9. Sự tác động của nghiện mạng xã hội với việc ngại giao tiếp, ít tham gia hoạt động tập thể $(n=195)$

\begin{tabular}{|c|c|c|c|c|}
\hline \multirow{2}{*}{$\begin{array}{c}\text { Nghiện mạng } \\
\text { xẫ hội }\end{array}$} & \multicolumn{2}{|c|}{ Ngại giao tiếp, ít tham gia hoạt động tập thể } & \multirow{2}{*}{$\begin{array}{c}\text { OR } \\
\text { (KTC 95\%) }\end{array}$} & \multirow{2}{*}{$\mathbf{p}$} \\
\hline & Có n(\%) & Không $n(\%)$ & & \\
\hline Có & $31(40,8)$ & $45(59,2)$ & \multirow{2}{*}{$\begin{array}{c}2,727 \\
(1,438-5,172)\end{array}$} & \multirow{2}{*}{0,020} \\
\hline Không & $24(20,2)$ & $95(79,8)$ & & \\
\hline
\end{tabular}

Học sinh bị nghiện mạng xã hội có tỷ lệ ngại giao tiếp, ít tham gia hoạt động tập thể cao gấp 2,727 lần (95\% CI: 1,438-5,172) so với học sinh không nghiện mạng xã hội. Sự khác biệt này có ý nghĩa thống kê với $p=0,02$.

Bảng 3.10. Tác động nghiện mạng xã hội với tình trạng mất tập trung trong học tập (n=195)

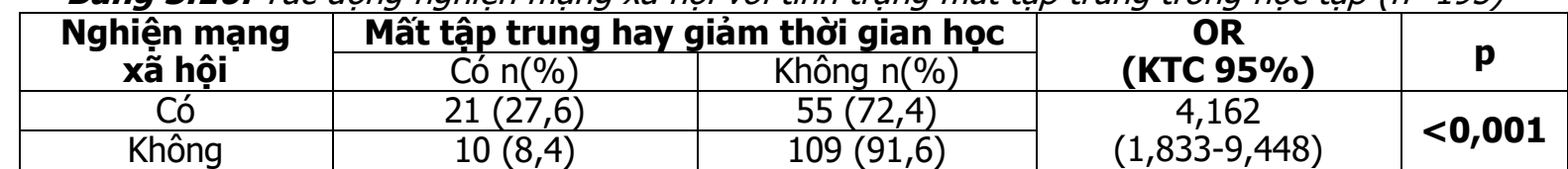

Học sinh bị nghiện mạng xã hội có tỷ lệ mất tập trung hay giảm thời gian học cao gấp 4,162 lần (95\% CI: 1,833-9,448) so với nhóm không bị nghiện mạng xã hội. Sự khác biệt này có ý nghĩa thống kê với $\mathrm{p}<0,001$.

Bảng 3.11. Sự tác động của nghiện mạng xã hội đên thị lực $(n=195)$

\begin{tabular}{|c|c|c|c|c|}
\hline \multirow{2}{*}{$\begin{array}{c}\text { Nghiện mạng xã } \\
\text { hội }\end{array}$} & \multicolumn{2}{|c|}{ Đau măt, khô măt hay giảm thị lực } & \multirow{2}{*}{$\begin{array}{c}\text { OR } \\
\text { (KTC 95\%) }\end{array}$} & p \\
\cline { 2 - 3 } & Có $n(\%)$ & Không $n(\%)$ & 1,975 & $\mathbf{0}, \mathbf{0 2 3}$ \\
\hline Có & $38(50,0)$ & $38(50,0)$ & $(1,096-3,559)$ & \\
\hline Không & $40(33,6)$ & $79(66,4)$ &
\end{tabular}

Học sinh bị nghiện mạng xã hội có tỷ lệ đau mắt, khô mắt hay giảm thị lực cao gấp 1,975 lần (95\% CI: 1,096-3,559) so với nhóm không nghiện mạng xã hội. Sự khác biệt này có ý nghĩa thống kê với $p=0,023$.

\section{BÀN LUÂ̂N}

Tỷ lệ nghiện: Trong khảo sát này, tỷ lệ học sinh nghiện internet khá cao chiếm $39 \%$ với số điểm trung bình nghiên theo thang đo IAT là $28,12+/-12,89$. Kết quả này có tỷ lệ cao hơn so với nghiên cứu của Nguyễn Thị Minh Ngọc (2017) ở học sinh phổ thông tỉnh Nam Định (37,1\%)[2], Trần Xuân Bách (2017) có 21,2\% giới trẻ Việt nghiện internet [8], nghiên cứu của Luca trên 98 thanh thiếu niên được khảo sát cho thấy tỷ lệ nghiện internet là 36,7\% [7]. Tỷ lệ nghiện internet có sự chênh lệch giữa các nghiên cứu, khác biệt này có thể gây ra bởi sự khác biệt trong phương pháp đánh giá mức nghiện, khác biệt về văn hóa xã hội cơ bản, độ tuổi đối tượng cũng như cõ̃ mẫu tham gia khảo sát. Tỷ lệ nghiện internet trong nghiên cứu khá cao nhưng cũng phù hợp với những điều tra trước cho rằng các nước châu Á có tỷ lệ nghiện tăng khá nhanh.

Các loại trang mạng: Instagram facebok, zalo, youtube, google, zing me là những trang mang xã hội được học sinh THCS sử dụng phổ biển hiện nay. Bển cạnh đó, kết quả nghiên cứu tìm thấy mối liên quan giữa sử dụng instagram và games với nghiện mạng xã hội. Có thể thấy học sinh sử dụng mạng instagram có tỷ lệ nghiện mạng xã hội cao gấp 2,442 lần so với nhóm không sử dụng mạng instagram. Học sinh sử dụng game có tỷ lệ nghiện mạng xã hội cao gấp 2,203 lần so với nhóm không sử dụng mạng game. 
Về học lực: Học sinh bị nghiện mạng xã hội thì có học lực trung bình, dưới trung bình cao gấp 2,142 lần so với học sinh không bị nghiện mạng xã hội, sự khác biệt này có ý nghĩa thống kê với $\mathrm{p}=0,033$. Kết quả này tương đồng với nghiên cứu của Kilic M (2016) cho kết quả là điểm nghiện (IAS) tăng lên khi thành tích học tập của học sinh kém đi với $p=0,03$ [4] và Jian Xu (2012) trên 5.122 thanh thiếu niên Trung Quốc cho kết quả nhóm có học lực không tốt bị nghiện internet chiếm $18,9 \%$ và với $p<0,0001$ [6]. Điều này có thể lí giải rằng do trên internet có thông tin da dạng, cập nhật nhanh, dễ tìm kiếm nên việc sử dụng công cự tìm kiếm trên intenet cũng khiến nhiều bạn trẻ trở nên lười suy nghĩ, lười tư duy. Có thể các em học sinh khi có bài tập ở nhà thì không chịu suy nghĩ, đọc sách tìm hiểu mà chỉ vào google tìm và sao chép nguyên văn những thứ có ở trên mạng, nhiều khi chỉ sao chép mà không chịu đọc. Chính vì thế mà làm cho các bạn trở nên thụ động trong học tập cũng như trong công việc, làm cho kết quả học tập cũng không khả quan.Nguyên nhân của nhóm học lực không tốt có tỷ lệ nghiện cao hơn có thể do các em thường có khả nẳng tự kiểm soát kém hơn, tự điều chỉnh kém hơn và nhận thức kém hơn so với dân số ở độ tuổi đại học hoă̆c người trưởng thành hay những bạn có tư duy tốt hơn. Mặt khác, ngày nay, việc sử dụng máy tính của thanh thiếu niên được khuyến khích, và trong một số khóa học là bắt buộc. Việc sử dụng internet là hợp lý và phổ biến ngay cả bên ngoài lớp học. Hầu hết các thư viện trường học, gia đình và quán cà phê internet đều có truy cập internet và các em có thể dễ dàng truy cập internet.

Chất lượng giấc ngủ: Nhóm học sinhhay bị nghiện mạng xã hội thì có chất lượng giấc ngủ không tốt cao gấp 3,749 so với nhóm học sinh không không bị nghiện mạng xã hội. Sự khác biệt này có ý nghĩa thổng kề với $p=0,01$. Kết quả này phù hợp với nghiên cứu của Ozalp Ekinci (năm 2014) với 1212 thanh thiếu niên tham gia nghiên cứu, kết quả cho thấy 16\% chất lượng giấc ngủ là xấu hoặc rất xấu. Tổng điểm trung bình của IAS (nghiện internet) là 35,56 \pm 13,87 . Thanh thiếu niển có điểm nghiện cao hơn báo cáo đi ngủ muộn hơn vào ban đêm, cần nhiều thời gian hơn để ngủ và có số lần thức giấc tăng lên trong đêm so với thanh thiếu niên có điểm nghiện thấp hơn $(p=0,001)$ [5]. Hay là nghiên cứu của Yafei Tan và cộng sự (2016) tại Trung Quốc cho tỷ lệ trong 17,2\% ở thanh thiếu niên bị nghiện thì 40,0\% thanh thiếu niên bị rối loạn giấc ngủ và nhận thấy có mối liên quan.
Giấc ngủ có một vai trò quan trọng trong cuộc sống của con người, đặc biệt đối với trẻ em và thanh thiếu niên. Mạng xã hội và internet đang có ảnh hưởng lớn đến cuộc sống của lớp trẻ. Do sự gia tăng mạnh mẽ việc sử dụng internet trong những năm gần đây, một số nghiên cứu cũng cảnh báo tác động tiêu cực của việc sử dụng internet quá mức đối với sức khỏe tâm thần.

Thụ động, ngại giao tiếp: Học sinh bị nghiện mạng xã hội có tỷ lệ ngại giao tiếp, ít tham gia hoạt động tập thể cao gẩp 2,727 lần so với học sinh khổng không nghiện mạng xã hội. Điều này có thể lý giải nhiều trẻ đang dành phẩn lớn thời gian chơi điện tử, xem truyền hình và sử dụng các mạng xã hội như facebook, zalo, viber,...và chỉ như đối thoại một mình.Vì vậy, các em dành rất ít thời gian để giao tiếp với các bạn đồng trang lứa hay bạn bè ở lớp, kỹ năng xã hội kém, cảm thấy rất khó để giao tiếp với mọi người, nhất là khi chúng ở vào độ tuổi trưởng thành, và điều này có thể gây hại cho cuộc sống của chúng trong thời gian dài

Về độ thiếu tập trung: Học sinh bị nghiện mạng xã hội có tỷ lệ mất tập trung hay giảm thời gian học cao gấp 4,162 lầnso với nhóm không bị nghiện mạng xã hội có ý nghĩa thống kê với $\mathrm{p}<0,001$. Kết quả có sự phù hợp với nghiên cứu của Yen JY năm 2007 được thực hiện với 2114 thanh thiếu niên cho thấy nghiện internet và rối loạn trầm cảm và các triệu chứng rối loạn thiếu tập trung/hiếu động thái quá đã tìm thây mối tương quan với nhau.

Về thị lực: Tỷ lệ đau mắt, khô mắt hay giảm thị lực cao gấp 1,975 lần so với nhóm không bị nghiện mang. Điểu này có thể giải thích đối với những đối tượng sử dụng internet có thời gian truy cập lâu, liên tục nhìn vào màn hình máy tính, điện thoại. Ngoài ra, khoảng cách giữa mắt và các thiết bị truy cập internet có thể không an toàn nên dễ bị đau mắt, khô mắt, có thể dẫn đến cận thị. Theo nghiên cứu của Lê Minh Công thì đau nhức mắt là hậu quả thứ 5 với các mức tỷ lệ là thường xuyên chiếm $48,7 \%$, thỉnh thoảng chiểm 43,6\% ở những đối tượng nghiện do việc sử dụng internet gây ra [1].

\section{KẾT LUẬN}

Nghiên cứu cho thấy mối liên quan giữa sự tác động nghiện mạng xã hội với sứ dụng instsgram, chất lượng giấc ngủ, ngại giao tiếp, ít tham gia các hoạt động tập thể của học sinh, mất tập trung hay giảm thời gian học, đau mắt/khô mắt/giảm thị lực, kết quả học tập của học sinh. Cần có kế hoạch truyền thông giáo dục sức khỏe phù hợp cho học sinh trường Trung 
học cơ sở Minh Trí tại Thành phố Trà Vinh nói riểng cũng như học sinh Trung học cơ sở nói chung về hành vi sử dụng mạng xã hội một cách phù hợp để không ảnh hưởng đến kết quả học tập cũng như cuộc sống của học sinh để góp phần làm nâng cao kết quả học tập của học sinh. Ngoài ra, cần đẩy manh chiến lược truyền thông giáo dục sức khỏe để giảm thiểu tỷ lệ suy dinh dưỡng ở học sinh.

\section{TÀl LIÊU THAM KHẢO}

1. Lê Minh Công (2013), "Tình trạng nghiện internet ở hoc sinh trung hoc cơ sở tai thành phố Biên Hòa tỉnh Đồng Nai", Tạp chí Khoa hoc tr1-13.

2. Nguyễn Thi Minh Ngọc (2017), "Thực trạng nghiện Internet của học sinh trường Trung học phổ thông Hải Hậu, tỉnh Nam Đinh năm 2017 và môt số yểu tố liên quan", Tạp chí Y học dự phòng.

3. Trân Minh Trí (2016), "Thực trạng sử dụng Internet và những tác đống của Internet đến sinh viên trường Đại học Nông lâm TP.HCM", Tạp chí
Nông lâm học, Đại học Nông lâm TP.HCM, tr1-11.

4. Kilic $\mathbf{M}$ and et al (2016), "Internet Addiction in High school Students in Turkey and Multivariate Analyses of the Underlying Factors", ] Addict Nurs, doi: 10.1097/JAN.0000000000000110.

5. Ozalp EKINCI and et al (2014), "Association between Internet use and sleep Problems in Adolescents", Noro Psikiyatr Ars, doi: 10.4274/ npa.y6751.

6. Jian $X u$ and et al (2012), "Personal characteristics related to the risk of adolescent internet addiction: a survey in Shanghai, China", BMC Public Health, doi:10.1186/1471-2458-12-1106.

7. Milani Luca and et al (2009), "Quality of interpersonal relationships and problematic internet use in adolescence", Cyberpsychol Behav, doi: $10.1089 / c p b .2009 .0071$.

8. Tran Xuan Bach and et al (2017), "A student on the influence of internet addiction and online interpersonal on health-related quality of life in young Vietnamese", BMC Public Health , doi: 10.1186/s12889-016-3983-z.

\title{
CÁC CẤP Độ KÉO DÀI TRỤ MŨI TRONG TẠO HÌNH MŨI TRÊN BỆNH NHÂN DI CHỨNG KHE HỞ MÔI VÒM
}

\author{
Vũ Thị Dung ${ }^{1}$, Phạm Kiến Nhật ${ }^{2}$, Phạm Tuấn $A_{n h}{ }^{2}$, \\ Lưu Phương Lan², Đỗ Tuấn Ngọc ${ }^{2}$, Hoàng Tuấn Anh ${ }^{1}$
}

\section{TÓM TẮT}

Mục tiêu của bài báo này là trình bày một cách tiễ̂́p cận theo các cấp độ để kéo dài trụ mũi trong phẫu thuật tạo hình mũi trên bệnh nhân di chứng khe hở môi - vòm dựa trên các đắc điểm nhân trắc học. Đây là nghiên cứu thuần tập hồi cứu trên các bênh nhân điều trị tại Bệnh viện Đại học Y Hà Nội từ năm 2017 đến năm 2021 . 18 bếnh nhân với biến dang môi - mũi di chứng khe hở mổi vòm được phẫu thuật tạo hình mũi với 4 phương pháp tiếp cận kéo dài trụ mữi gồm: vạt dồn đẩy $V-Y$ (10 bệnh nhân), vạt xoay đẩy theo Millard (3 bệnh nhân), vạt folked (3 bệnh nhân) và vạt Abbé ( 2 bệnh nhân). Kết quả được đánh giá bằng cách sử dụng hệ thống chấm điểm theo bảng câu hỏi "Đánh giá kết quả tạo hình mũi" (ROE) và hệ thống chấm điểm Mortier. 4 thông số đo lường nhân trắc học được thu thập để định lượng và đánh giá khách quan. Thời gian theo dõi trung bình là 9 tháng. Mức độ biến dạng ban đầu trung bình là 22,72 $\pm 5,99$ điểm và kết quả sau phẫu thuật là $72,58 \pm 11,45$ điểm theo bộ câu hỏi "Đánh giá kết quả tạo hình mũi (ROE)". Phương pháp tiếp cận kéo dài trụ mũi theo các cấp độ

\footnotetext{
${ }^{1}$ Bệnh viện Đại học Y Hà Nội

${ }^{2}$ Trường Đại học Y Hà Nội

Chịu trách nhiệm chính: Vũ Thị Dung

Email: vuthidung.ptth@gmail.com

Ngày nhận bài: 24/8/2021

Ngày phản biện khoa học: 22/9/2021

Ngày duyệt bài: 3/10/2021
}

đã cho thấy kết quả tốt, tỷ lệ bệnh nhân hài lòng cao và tỷ lệ biến chứng thấp.

Tư khóa: Khe hở môi - vòm, tạo hình mũi, kéo dài trụ mũi.

\section{SUMMARY \\ GRADUATED APPROACH TO LENGTHENING COLUMELLA IN CLEFT RHINOPLASTY}

The purpose of this article was to present a graduated approach to lengthening columella in cleft rhinoplasty based on antropometric features. This was a retrospective cohort study of patients treated at the Hanoi Medical University Hospital from 2017 to 2021. 18 patients underwent rhinoplasty with four approaches include: $\mathrm{V}-\mathrm{Y}$ plasty (10 patients), rotationadvancement flap (3 patients), Forked flap (3 patients) and Abbé flap (2 patients). Outcomes were assessed by using a Rhinoplasty Outcome Evaluation (ROE) questionnaire and the Mortier scoring system. 8 parameters of anthropometric measurement were collected for objective evaluation. Of the 18 patients enrolled in the study, 10 were women and 8 were men. Mean follow-up period was 9 months. The average degree of initial deformity was $22.72 \pm 5.99$ and postoperative result was $72.58 \pm 11.45$ according to the "Rhinoplasty Outcome Evaluation (ROE)". The graduated approach has shown excellent outcomes, a high rate of patient satisfaction, and a low rate of complication.

Keywords: Cleft lip and palate, rhinoplasty, columella lengthenning. 